\title{
Cell cycle-dependent transcription factors control the expression of yeast telomerase RNA
}

\author{
ISABELLE DIONNE, ${ }^{1}$ STÉPHANIE LAROSE, ${ }^{1}$ ALAIN T. DANDJINOU, SHERIF ABOU ELELA, \\ and RAYMUND J. WELLINGER ${ }^{2}$ \\ RNA Group, Department of Microbiology and Infectiology, Faculty of Medicine and Health Sciences, Université de Sherbrooke, \\ Sherbrooke, Quebec, J1E 4K8, Canada
}

\begin{abstract}
Telomerase is a specialized ribonucleoprotein that adds repeated DNA sequences to the ends of eukaryotic chromosomes to preserve genome integrity. Some secondary structure features of the telomerase RNA are very well conserved, and it serves as a central scaffold for the binding of associated proteins. The Saccharomyces cerevisiae telomerase RNA, TLC1, is found in very low copy number in the cell and is the limiting component of the known telomerase holoenzyme constituents. The reasons for this low abundance are unclear, but given that the RNA is very stable, transcriptional control mechanisms must be extremely important. Here we define the sequences forming the TLC1 promoter and identify the elements required for its low expression level, including enhancer and repressor elements. Within an enhancer element, we found consensus sites for Mbp1/Swi4 association, and chromatin immunoprecipitation (ChIP) assays confirmed the binding of Mbp1 and Swi4 to these sites of the TLC1 promoter. Furthermore, the enhancer element conferred cell cycle-dependent regulation to a reporter gene, and mutations in the Mbp1/Swi4 binding sites affected the levels of telomerase RNA and telomere length. Finally, ChIP experiments using a TLC1 RNA-binding protein as target showed cell cycle-dependent transcription of the TLC1 gene. These results indicate that the budding yeast TLC1 RNA is transcribed in a cell cycle-dependent fashion late in G1 and may be part of the $S$ phase-regulated group of genes involved in DNA replication.
\end{abstract}

Keywords: telomerase; ribonucleoprotein; telomere; DNA replication; cell cycle

\section{INTRODUCTION}

The ends of eukaryotic chromosomes, the telomeres, are composed of tandem repeated DNA sequences that are bound by specific proteins to form specialized structures. They protect chromosome ends from degradation and unwarranted repair attempts, thereby preserving genome stability (O'Sullivan and Karlseder 2010; Wellinger and Zakian 2012). Furthermore, the conventional DNA replication machinery being unable to fully replicate both strands of a DNA-end, the ribonucleoprotein (RNP) telomerase is required to maintain a functional tract of telomeric DNA and hence to protect the integrity of chromosomes (Egan and Collins 2012; Wellinger and Zakian 2012). An absence or insufficiency of telomerase eventually leads to nonfunctional end-capping and genomic rearrangements, common preludes to cancer or other syndromes in humans. For example, mutations in genes coding for core moieties of the telomerase RNP, including its RNA component, can lead to congenital diseases such as dyskera-

\footnotetext{
${ }^{1}$ These authors contributed equally to this work.

${ }^{2}$ Corresponding author

E-mail Raymund.Wellinger@USherbrooke.ca

Article published online ahead of print. Article and publication date are at http://www.rnajournal.org/cgi/doi/10.1261/rna.037663.112.
}

tosis congenita, even if the individuals are only heterozygous for the mutations (Wong and Collins 2006). Haploinsufficiency for the RNA component is also observed in diploid budding yeast (Mozdy and Cech 2006). Therefore, the expression of telomerase components must be tightly balanced and regulated, yet little is known about the processes leading to this strict control.

Protein components of the telomerase holoenzyme include a conserved catalytic subunit similar to reverse transcriptases but also comprise other subunits essential for in vivo activity (Autexier and Lue 2006). Additional proteins are involved in RNP biogenesis and trafficking (Gallardo et al. 2008; Wellinger and Zakian 2012). The RNA component varies widely in size and sequence between species, but conserved secondary and tertiary structural elements have been identified, notably a single-stranded region serving as template for telomeric repeat synthesis and a pseudo-knot structure (Lin et al. 2004). This part of the RNA is associated with the reverse transcriptase component and can be seen as the catalytic core of the RNP.

The budding yeast telomerase RNA, called TLC1, is a 1157-nucleotide (nt) transcript generated by RNA polymerase II and occurs in two different forms: the mature nonpolyadenylated form (90\%-95\% of the total RNA) and a minor 
form that is larger and polyadenylated (5\%-10\% of the RNA) (Chapon et al. 1997; Bosoy et al. 2003). Generation of the mature nonpolyadenylated 3 -end occurs via the Nrd1-dependent noncoding RNA termination pathway (Jamonnak et al. 2011; Noël et al. 2012). The RNA has been proposed to fold into a distinct structure that may function as a central scaffolding element for the RNP (Dandjinou et al. 2004; Zappulla and Cech 2004; Lebo and Zappulla 2012). At steady state, there are about 30 molecules of TLC1 RNA per cell (Mozdy and Cech 2006), which is apparently less than any of the protein components of telomerase (Tuzon et al. 2011). It is thus likely that the TLC1 RNA is the limiting factor for RNP generation. The reasons for this low abundance of the TLC1 RNA are unclear. The RNA as such shares features with snRNA (trimethylguanosine cap, Sm binding near the mature $3^{\prime}$-end) and is very stable with a half-life of $>60 \mathrm{~min}$, while the average yeast mRNA half-life is $\approx 20 \mathrm{~min}$ (Seto et al. 1999; Wang et al. 2002; Larose et al. 2007; Wellinger and Zakian 2012). Therefore, its low abundance is unlikely due to high instability, but rather its expression must be tightly regulated to allow only low generation rates. Consistently, deletions of certain transcription factor genes or genes affecting the efficiency of 3 '-end formation of the TLC1 RNA impinge on the steady-state level of the mature RNA and also affect telomere length (Mozdy et al. 2008). For example, the Paf1C complex is somehow involved in establishing the average level of the TLC1 RNA, but it remains to be determined whether this is a direct effect and whether it occurs at transcription initiation or another step of RNA production (Mozdy et al. 2008). Thus, while it is becoming clear that the generation of a sufficient amount of mature TLC1 transcript is critical for telomerase function and the keeping of a functional telomeric repeat tract, virtually nothing is known about its transcriptional regulation.

In yeast, telomeric regions are replicated in late $S$ phase (McCarroll and Fangman 1988; Raghuraman et al. 2001). The action of telomerase coincides with this timeframe as it acts on telomeres during late S/G2 phase of the cell cycle (Diede and Gottschling 1999; Marcand et al. 2000; Gallardo et al. 2011). This cell cycle-restricted access of telomerase to telomeres is imposed, at least in part, by the Rif-proteins, but a direct cell cycle-dependent regulation of the holoenzyme or the expression of components thereof may also contribute (Gallardo et al. 2011). Among the telomerase components, only the abundance of Est1 has been reported to be cell cycle-regulated, being low in G1 and higher in late S/G2 (Taggart et al. 2002; Wu and Zakian 2011). The degradation of the Est1 protein at the entry into G1 is proteasome dependent, but the RNA levels are also fluctuating during the cell cycle (Spellman et al. 1998; Osterhage et al. 2006; Larose et al. 2007).

Here we used phylogenetic methods to define candidate promoter elements in the Saccharomyces cerevisiae telomerase RNA gene, with the goal of identifying the elements influencing its expression and examining potential transcriptional regulation. Systematic targeted deletions upstream of the TLC1 $5^{\prime}$-end defined its core transcriptional promoter and also uncovered repressor and enhancer elements. The most highly conserved elements in this promoter included potential consensus sites for the binding of the Mbp1/Swi4 transcriptional enhancers. Indeed, chromatin immunoprecipitation (ChIP) assays confirmed the binding of Mbp1 and Swi4 to the TLC1 promoter. Consistent with a functional relevance for the specific sequences, site-directed point mutations within the consensus binding sites caused reduced levels of telomerase RNA and short telomeres. Furthermore, an RNA binding protein-linked ChIP (RBP-ChIP) approach showed cell cycle-dependent transcription of the TLC1 gene. These results indicate that the budding yeast TLC1 RNA is transcribed in a cell cycle-dependent fashion late in G1 and may be part of the S phase-regulated group of genes involved in DNA replication.

\section{RESULTS}

\section{Dissection of the TLC1 transcription promoter}

While the structure of the yeast telomerase RNA itself has been the subject of intense study, its promoter remains poorly defined. We compared the sequences $5^{\prime}$ of $T L C 1$, up to the adjacent gene, $P D X 3$, to look for potential regulatory elements by sequence conservation among a multiplicity of Saccharomyces "sensu stricto" yeast strains. (Supplemental Fig. $\mathrm{S} 1$, for reference, the +1 site is the major $5^{\prime}$-end on the mature TLC1 RNA as determined in Dandjinou et al. 2004). The nonessential snRNA gene snR161 ( -252 to -412$)$ that is included in this region (Olivas et al. 1997; Torchet et al. 2005) is well conserved $(53 \%-69 \%)$. As expected for promoter regions, the conservation of the sequences located between the PDX3 and snR161 genes ( -644 to -412$)$ and between the two divergent transcribed genes snR161 and TLC1 ( -242 to +1 ) is low, ranging from $14 \%-42 \%$ (Fig. $1 \mathrm{~A}$; Supplemental Fig. S1). We searched the first $200 \mathrm{bp}$ upstream of the $5^{\prime}$-end of TLC1 for the binding site of the basal transcription factor TATA binding protein (TBP) (Hampsey 1998), which is normally found $40-120$ bp from the transcription initiation site in yeast (Smale and Kadonaga 2003; Kuehner and Brow 2006). Surprisingly and in contrast to other noncoding RNA promoters in yeast, no highly conserved canonical TATA box or initiation site consensus could be identified (Supplemental Fig. S1; Kuehner and Brow 2006). Instead, we found several weakly conserved TATAGA elements and more conserved TATATCTAAA and TATATCA sequences at -75 , -171 , and $-221 \mathrm{bp}$ from the transcription start, respectively. This lack of a strong consensus element suggests that multiple degenerate transcription initiation sites are used (Supplemental Fig. S2; Dandjinou et al. 2004). However, since no promoter could be identified via phylogeny, we delineated sequence elements according to similarities (see Fig. 1A; Supplemental Fig. S1). Of note, the stretch of highest sequence 
A

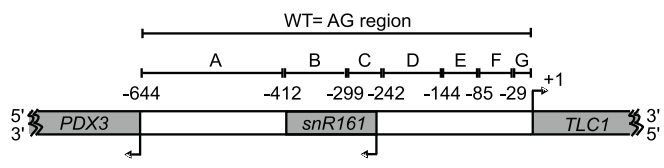

B

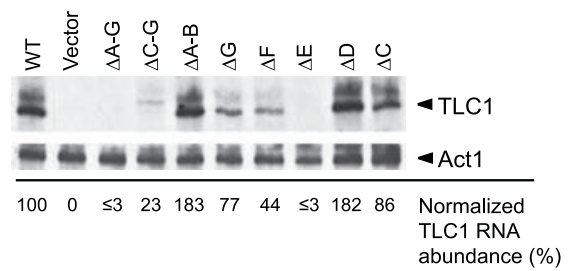

C

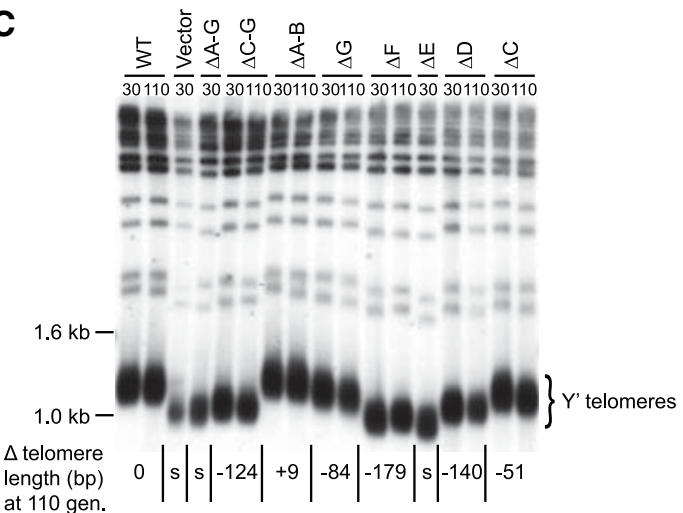

FIGURE 1. Identification of promoter elements required for TLC1 expression and function. (A) Schematic representation of the TLC1 chromosomal locus and the flanking upstream genes. The start codon of $P D X 3$ as well as the $5^{\prime}$-ends of the mature snR161 and TLC1 RNAs are represented by arrows indicating the transcription direction. The identity of the conserved sequence motifs is indicated by letters. $(B)$ Northern blot analysis of TLC1 RNA isolated from cells harboring different deletions in the TLC1 promoter. TLC1 RNA abundance was normalized to Act1 mRNA and is presented as an average of three experiments with a SD of $\pm 20 \%$ or less. $(C)$ Southern blot analysis of telomere length of the different strains examined in $B$. The DNA was extracted from individual yeast clones grown for 30 or 110 generations, digested with XhoI, and separated on an Agarose gel. The different fragments were visualized using a randomly labeled probe complementary to the telomeric sequence. Note that strains harboring vector only (Vector), a complete deletion of the intergenic sequences $(\Delta A-G)$, or a deletion of the E element $(\Delta \mathrm{E})$ could not be cultured beyond 40 generations, and thus, only DNA derived from cultures grown for 30 generations was analyzed. Changes in $\mathrm{Y}^{\prime}$ telomere length for cells grown for 110 generations are indicated at the bottom. S denotes senescing cells that have unstable telomere length.

conservation was in region E ( -85 to -144) (Fig. 1A, Supplemental Fig. S1; see below). We deleted the various elements within plasmids containing the entire TLC1 locus and assessed the effect on TLC1 expression and telomerase activity in strains that lack both TLC1 and RAD52 genes (Dandjinou et al. 2004). As expected, the plasmid carrying the entire locus (WT) supported normal growth (Table 1), normal TLC1 RNA expression (Fig. 1B), and normal telomere length (Fig. 1C), while the empty vector (Vector) did not. Primer extension analysis of RNA extracted from cells harboring the WT plasmid confirmed the previously established major $(+1)$ and several minor transcription start sites (Supplemental Fig. S2;
Dandjinou et al. 2004). These sites and the ratio of the polyadenylated to nonpolyadenylated TLC1 RNA were similar to those expressed from the chromosomal copy of TLC1 (Dandjinou et al. 2004; data not shown). Deletion of the entire region upstream of TLC1 $(\triangle \mathrm{A}-\mathrm{G})$ blocked the expression of both polyadenylated and nonpolyadenylated RNA and inhibited cell growth after 40-50 generations as observed with the empty vector (Fig. 1B; Table 1). Deletion of the most upstream region $(\triangle \mathrm{A}-\mathrm{B})$ did not affect growth or reduce telomere length, suggesting that this region is not part of the TLC1 promoter. Deleting the region between $s n R 161$ and the TLC1 transcription start site $(\triangle \mathrm{C}-\mathrm{G})$ did not completely abolish RNA expression (Fig. 1B) and allowed the maintenance of very short telomeres (Fig. 1C). However, the expressed RNA species are significantly extended on the $5^{\prime}$-end (Fig. 1B; Supplemental Fig. S2) yet had a normal $3^{\prime}$-end (data not shown), suggesting the activity of a cryptic promoter within the region A-B. Individual deletions of the regions $\mathrm{C}$ and $\mathrm{D}$ did not inhibit transcription or growth (Fig. 1B; Table 1). Curiously, deletions of either region D or A-B slightly increased the level of TLC1, implying that these regions negatively regulate TLC1 expression (Fig. 1B). In contrast, deletion of region E, which is the most conserved region found between TLC1 and snR161, completely abolished transcription (Fig. 1B; Supplemental Fig. S2), caused a loss of telomeric sequences (Fig. $1 \mathrm{C}$ ), and led to growth arrest (Table 1). Deletion of region F that contains the most proximal TATA box-like sequence severely inhibited transcription and resulted in reduced telomere sizes; however, the cells did not exhibit growth arrest (Fig. 1; Table 1). Deleting the region immediately upstream of TLC1 $(\Delta \mathrm{G})$ reduced transcription and moderately decreased telomere length. All these deletions affected similarly the expression of both the polyadenylated and nonadenylated forms of TLC1. This suggests that the promoter elements control all forms of TLC1, regardless of the nature of their 3 '-end. Collectively, these data suggest that the core TLC1 promoter is composed of elements E-F-G ( +1 to -144$)$ requiring the enhancer in element $\mathrm{E}$, which may thus be multifunctional. However, additional transcriptional regulation is conferred by the repressing sequences in element $\mathrm{D}(-144$ to -242$)$.

\section{The promoter of $T L C 1$ can support the transcription of a reporter gene}

It was previously shown that heterologous mRNA polymerase II promoters can support the expression of the TLC1 RNA (Chapon et al. 1997), but the capacity of the TLC1 promoter to drive heterologous mRNA expression is not known. In order to clarify this point and to further define the core TLC1 promoter, we cloned various fragments of the promoter upstream of a lacZ reporter gene (Fig. 2A) and monitored RNA expression by Northern blots. No RNA was detected from the empty lac $Z$ vector, as expected. In contrast, the introduction of the entire TLC1 upstream region (A-G) resulted in the expression of a single band corresponding to the 
TABLE 1. Complementation of $T L C 1$ functions by different promoter deletions

\begin{tabular}{|c|c|c|c|c|c|c|c|c|c|}
\hline \multirow{2}{*}{$\begin{array}{l}\text { TLC1 } \\
\text { Promoter } \\
\text { constructs }\end{array}$} & \multicolumn{4}{|c|}{$\begin{array}{l}\text { Growth with } T L C 1 \text { plasmid } \\
\text { (generations) }\end{array}$} & \multirow{2}{*}{$\begin{array}{c}\text { Loss of } \\
\text { plasmid }^{b} \\
120\end{array}$} & \multicolumn{4}{|c|}{$\begin{array}{l}\text { Growth without } T L C 1 \\
\text { plasmid }^{(\text {generations) }}{ }^{\mathrm{C}}\end{array}$} \\
\hline & 40 & 60 & 80 & 100 & & 140 & 160 & 180 & 200 \\
\hline WT & + & + & + & + & + & + & $+/-$ & $+/-$ & - \\
\hline Vector & $+/-$ & - & & & & & & & \\
\hline$\Delta \mathrm{A}-\mathrm{G}$ & $+/-$ & $+/-$ & - & & & & & & \\
\hline$\Delta \mathrm{C}-\mathrm{G}$ & + & + & + & + & - & & & & \\
\hline$\Delta \mathrm{A}-\mathrm{B}$ & + & + & + & + & + & + & $+/-$ & - & \\
\hline$\Delta \mathrm{G}$ & + & + & + & + & + & $+/-$ & $+/-$ & - & \\
\hline$\Delta \mathrm{F}$ & + & + & + & + & + & $+/-$ & $+/-$ & - & \\
\hline$\Delta \mathrm{E}$ & + & $+/-$ & - & & & & & & \\
\hline$\Delta \mathrm{D}$ & + & + & + & + & + & + & $+/-$ & - & \\
\hline$\Delta \mathrm{C}$ & + & + & + & + & + & + & + & $+/-$ & - \\
\hline
\end{tabular}

${ }^{a}$ The ability of the different TLC1 promoter constructs to complement senescence of a double-mutant spore (t/c14, rad524) derived from CSHY76 was assessed by growth on YCTRP-LEU-URA medium over 100 generations. A plasmid containing a copy of the wild-type gene was used as a positive control, and an empty plasmid was used as a negative control. Growth was scored using two independent clones for each TLC1 promoter deletion.

${ }^{b}$ Plasmid dependence for survival was established by plating cells reaching 100 generations on 5-FOA for an additional 20 generations to lose the TLC1 containing plasmids. The resulting cells were further grown on YC-TRP-LEU medium for up to 200 generations.

$\mathrm{c}_{+}$indicates number and colony sizes similar to wild type; $+/-$, heterogeneous colony sizes with few normal sized colonies; and -, absence of growth.

tected from the intact $C Y C 1$ promoter (CYC1 pro-lacZ). Deletion of the CYC1 natural activator (CYC1 UAS $\triangle$ pro-lacZ) blocked the reporter expression. Interestingly, replacement of the $C Y C 1$ UAS with TLC1 E region (CYC1 UAS $_{\text {TLC1E }}$ prolacZ) dramatically increased RNA expression even above the level observed with CYC1 UAS pro-lacZ, indicating that $T L C 1 \mathrm{E}$ is a stronger enhancer. As expected, insertion of a fragment of the ACT1 coding region between the $C Y C 1$ UAS and the reporter gene $\left(C Y C 1 \mathrm{URS}_{A C T 1}\right.$ pro-lacZ) did not inhibit the expression. On the other hand, a known repressor

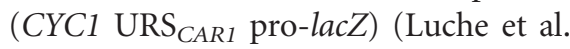
$1990)$ or the TLC1 region D (CYC1 $\mathrm{URS}_{\text {TLCID }}$ pro-lacZ) completely repressed transcription. We conclude that the TLC1 promoter is regulated by enhancer and suppressor sequences, respectively, located at -85 to -144 (E) and -144 to -242 bp (D) with respect to the transcription start site. Therefore, this region consti-

predicted size of lacZ (Fig. 2B; data not shown). This confirms the $T L C 1$ promoter's capacity to direct transcription of protein coding mRNA. Expression from the A-B region containing the newly identified cryptic $T L C 1$ promoter was slightly above background (Fig. 2B). All fragments containing region E (C-G, D-G, and E-G) supported expression, while the one without it (F-G) did not (Fig. 2B). Interestingly, the removal of the presumed repressor of $T L C 1$ transcription (D) dramatically increased lacZ transcription. On the other hand, the region $\mathrm{E}$ did not support transcription on its own, suggesting that $\mathrm{E}$ is not sufficient for initiation but rather works as an enhancer. These results confirm that the first 242 bp upstream of TLC1 are both necessary and sufficient for transcription and thus comprise the TLC1 promoter.

\section{TLC1 promoter activity is regulated by a balance between an enhancer and a repressor element}

The promoter deletion study and the lac $Z$ reporter analyses show that repressor (D) and enhancer (E) elements regulate $T L C 1$ transcription. To directly test this possibility, we used a model system based on a CYC1 promoter that can be regulated by heterologous activator or repressor sequences (Fig. 2C). The CYC1 core promoter and its natural upstream activator sequence (UAS) were described (Guarente and Ptashne 1981; Guarente and Mason 1983). Transcription from the intact CYC1 promoter or the different TLC1-CYC1 fusions was monitored by Northern blot using probes specific for lac $Z$ mRNA. As shown in Figure 2D, no expression was detected from the empty lac $Z$ vector, while strong expression was de- tutes the core promoter of TLC1.

\section{Mutation of the Mbp1 consensus binding site in TLC1 affects RNA expression and telomere length}

Careful analysis of the very conserved sequences found in element $\mathrm{E}$ revealed the presence of putative Mbp1 and Swi4 consensus binding sites called MCB (MluI Cell-cycle Box) and SCB (Swi4 Cell-cycle Box) (Fig. 3A; Supplemental Fig. S1; Taba et al. 1991; Harbison et al. 2004). Swi4 and Mbp1 are transcription factors that, in complex with Swi6, bind to the promoter of genes expressed during the G1/S transition. The consensus sequence for an MCB is DCGCGH (Badis et al. 2008), whereas the one for SCB is CGCSAAA (Harbison et al. 2004). In the TLC1 promoter, there is an overlapping $\mathrm{MCB} / \mathrm{SCB}$ motif at -108 (hereafter called MCB1) and a second MCB motif at -120 (MCB2, see Fig. $3 \mathrm{~A})$. In order to examine whether these potential MCB sites impact transcription of TLC1, we mutated the motifs in the plasmid containing the entire TLC1 locus. Mutating the MCB1 or MCB2 motifs separately only slightly decreased TLC1 RNA levels (Fig. 3B,C) and did not have a significant effect on the telomere length (Fig. 4A). On the other hand, combining both mutations (mcb1/2) reduced TLC1 levels to $\approx 20 \%$ of the WT levels (Fig. 3B,C). This reduction is paralleled by a sharp decrease in telomere length (Fig. 4A,B). However, this low amount of TLC1 RNA is sufficient to maintain telomeres for up to 200 generations of growth without cellular senescence (Fig. 4B; data not shown). Identical results were obtained with two different mutation combinations in 
A

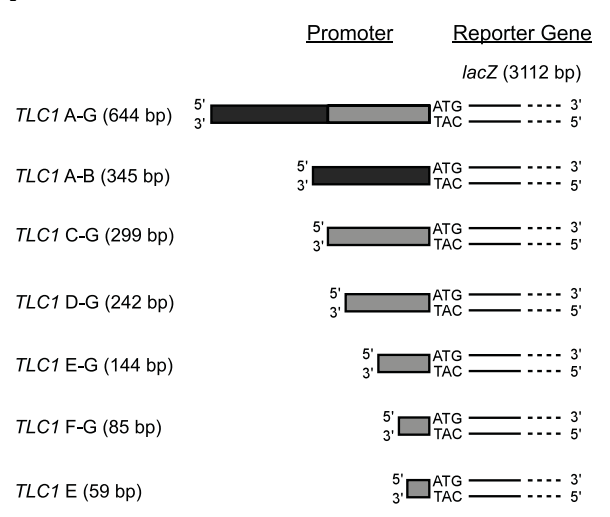

C

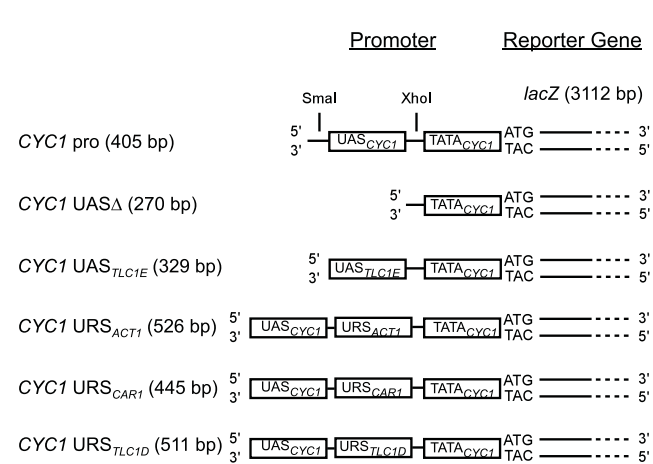

B

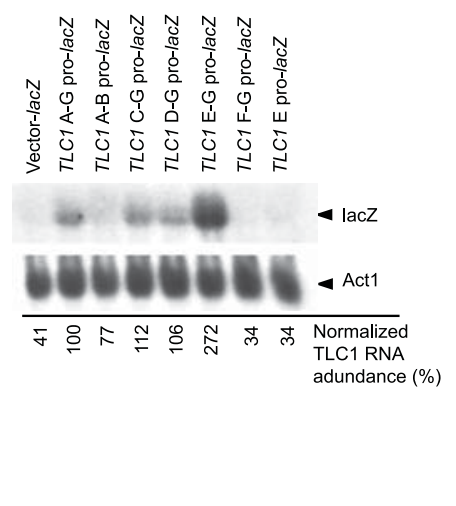

D

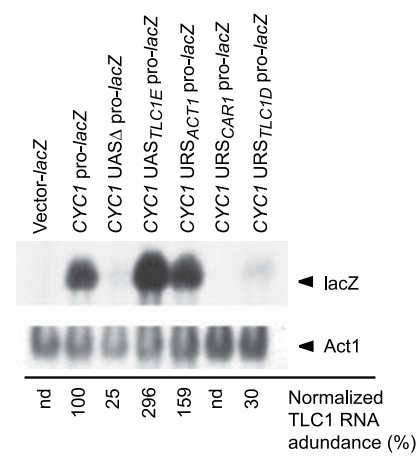

FIGURE 2. Defining TLC1 transcription enhancers and repressors using a transcription reporter system. (A) Schematic representation of the different TLC1 promoter regions cloned upstream of the lacZ reporter gene. Gray boxes indicate the sequence near the TLC1 $5^{\prime}$-end, while black boxes indicate the region encompassing $s n R 161$ and the region upstream. (B) Northern blot analysis of the lacZ RNA expressed from different TLC1 promoter regions. Total RNA was extracted from cells carrying the different TLC1 promoter-lacZ fusions, separated on Agarose gel, and visualized using an end-labeled oligonucleotide probe complementary to the lac $Z$ sequence. TLC1 RNA abundance was determined as in Figure 1 and is an average of three experiments with a SD of $\pm 39 \%$ or less. (C) Schematic representation of different CYC1-TLC1 promoter regions cloned upstream of the lac Z reporter. The $C Y C 1$ promoter was used as a test promoter to verify repressing and enhancing activity of the different $T L C 1$ promoter elements. The $C Y C 1$ promoter is represented by two empty boxes: One refers to the core element $\left(\right.$ TATA $\left._{C Y C 1}\right)$; the other, to the upstream activating sequence of CYC1 $\left(\mathrm{UAS}_{C Y C 1}\right)$. Constructs containing the TLC1 promoter regions $\mathrm{E}$ and $\mathrm{D}$ are indicated by $\mathrm{UAS}_{T L C 1 E}$ and $\mathrm{URS}_{T L C 1 D}$, respectively. $\mathrm{URS}_{A C T 1}$ indicates a construct carrying a fragment of the internal coding sequence of $A C T 1$ gene as a negative control. The known repressor sequence upstream of the CAR1 gene was used as a positive control ( $\left.\mathrm{URS}_{C A R I}\right)$. (D) Northern blot analysis of lacZ RNA expressed from the different CYC1-TLC1 constructs. The RNA was prepared and detected as in B. TLC1 RNA abundance is an average of three experiments with a SD of $\pm 88 \%$ or less. nd stands for nondetected RNA.

the MCB motif (mcb1/2a or mcb1/2b) (see Figs. 3A, 4A,B), eliminating the possibility that a fortuitous effect of the introduced mutations caused the short telomere phenotype. In yeast cells that lack Swi4 or Swi6 altogether, TLC1 RNA expression from its genomic locus also was slightly reduced (Supplemental Fig. S3). These results show that the discovered MCB motifs had a functional impact on telomerase expression. We then performed ChIP analysis using Swi4myc or Mbp1-myc tagged proteins in order to confirm the binding of the Swi4 and Mbp1 transcription factors to these
MCB sites in vivo. Quantitative assessment of the enrichment of the TLC1 promoter sequences confirmed the binding of both Swi4 and Mbp1 (Fig. 3D), while on mutated MCB-sites, no Swi4 binding could be detected (Fig. 3E). We conclude that the MCB motifs present in the TLC1 promoter are bound by the G1/S transcription factors and regulate TLC1 transcription and telomere homeostasis.

\section{The MCB motifs found in TLC1 confer cell cycle regulation}

It is well established that either Swi4 or Mbp1 can form a complex with Swi6 and act as transcription factors for genes that are induced at the G1/S transition (Koch et al. 1993; Wittenberg and Reed 2005). Yet, it was reported that the amount of total TLC1 RNA extracted from cell cultures does not vary significantly during the cell cycle (Fisher et al. 2004; Mozdy and Cech 2006). In order to analyze whether new TLC1 RNA synthesis occurs in a cell cycle-dependent manner, we resorted to RBP-ChIP (see Fig. 5A). In these experiments, the TLC1 RNA was expressed at its endogenous genomic locus and the RNA contained a 10xMS2 stem-loop tag near its mature $3^{\prime}$-end (Gallardo et al. 2011). These cells also expressed an MS2-ProA fusion protein, and cell cultures were synchronized using a-factor arrest in G1. At various time-points after release into a synchronous cell cycle, aliquots of the cultures cells were treated with formaldehyde and extracted as in a ChIP protocol. Finally, the MS2-ProA protein was immunoprecipitated with IgG beads and, the amount of coprecipitating DNA was measured by qPCR. This RBP-ChIP technique is thus expected only to detect TLC1 genes that are actually being transcribed and will not detect any already-made RNA that had moved away from the locus. DNA sequences $\approx 1 \mathrm{~kb}$ upstream of the MS2-tag insertion were never found to coimmunoprecipitate, probably due to the length of the RNA and random breaking during the chromatin isolation protocol (Fig. 5B). Furthermore, no coimmunoprecipitation was detected in extracts from cells with untagged RNA or in extracts treated with RNase. However, sequences immediately downstream from where the tags were located did coimmunoprecipitate and were significantly enriched in samples 
A
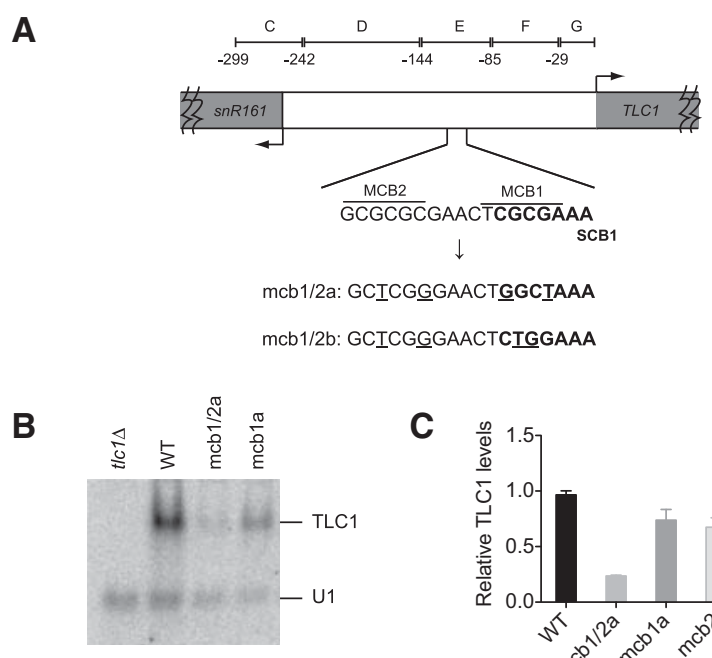

C

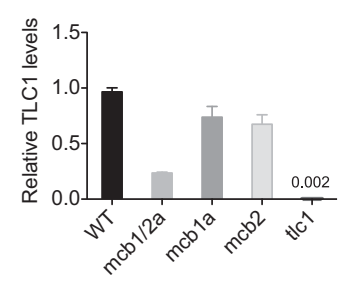

D

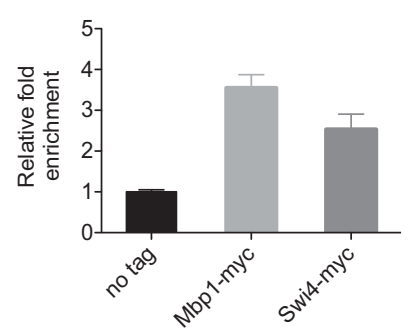

E

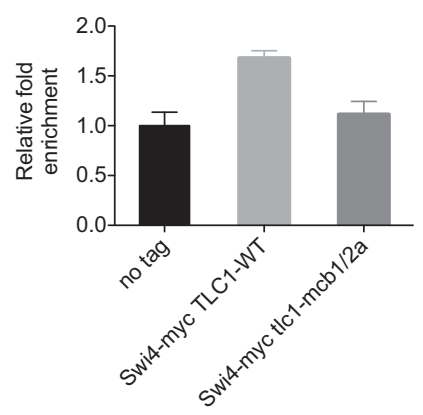

FIGURE 3. Mutations in the Mbp1/Swi4 consensus binding sites (MCB/SCB) affect TLC1 transcription levels. (A) Schematic representation of the TLC1 chromosomal locus and the flanking upstream gene. The 5'-ends of the mature snR161 and TLC1 RNAs are represented by arrows indicating the transcription direction. The identity of the conserved sequence motifs is indicated by letters. The region containing the putative $\mathrm{MCB} / \mathrm{SCB}$ motifs is magnified at bottom. The sequence of SCB1 is in bold, and the sequences of MCB1 and MCB2 are indicated by a line. The point mutations are indicated beneath. The mutant mcb1/2a was used in all the experiments except in Figure 4B, where it was mutant mcb1/2b. (B) Northern blot analysis of TLC1 RNA from CSHY76 $($ tlc1 $\Delta)$ or CSHY76 carrying TLC1 (WT) or tlc1-mcb1 (mcbla) or $t l c 1-m c b 1 / 2 a(m c b 1 / 2 a)$. Total RNA was extracted from log-phase cells, separated on an Agarose gel, and visualized using radioactive probes complementary to TLC1 and the U1 snRNA as a loading control. $(C)$ The same RNA samples used in $B$ were analyzed by qRTPCR. The TLC1 RNA levels were measured and normalized against Actl. The WT value is arbitrarily set to one. (D) ChIP analysis of Mbp1-myc (Z1372) and Swi4-myc (Z1335) on the genomic TLC1 promoter. Enrichment levels were determined by qPCR and are represented as the fold increase over the untagged strain (Z1256). Average value and error bars are derived from biological duplicates and experimental duplicates. (E) ChIP analysis of Swi4-myc on the genomic WT TLC1 promoter (IDY1014-3a) or the mutated $t l c 1-m c b 1 / 2$ promoter (IDY1014$6 c)$. Enrichment levels were determined by qPCR and are represented as the fold increase over the untagged strain (Z1256). Average value and error bars are derived from biological duplicates.

obtained 20 and 40 min after the release from the G1 arrest (Fig. 5B; data not shown). In G1-arrested cells and after 60 min of release, the amount of coimmunoprecipitated material was significantly reduced, showing that new TLC1 transcrip-

tion is induced early after the G1 release and concomitant with the induction of the G1/S marker Cln2 mRNA (Fig. 5C).

In order to confirm the cell-cycle phase-dependent regulation of TLC1 transcription by the MCB motifs, we used the CYC1-lacZ reporter constructs containing the region $\mathrm{E}$

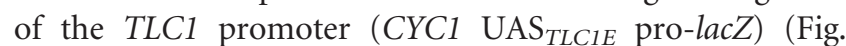
2C). As above, cells were arrested in G1 with $\alpha$-factor and released into a synchronized cell cycle, followed by RNA analysis by Northern blots and/or qRT-PCR at regular intervals after the release. Consistent with the RBP-ChIP above, when lac $Z$ transcription is driven by the promoter with the $\mathrm{UAS}_{T L C 1 E}$, there is a peak of expression at the 20- and 40min time points (Fig. 5D,E). However, when the MCB motifs are mutated (UAS-TLC1 $1_{E}$-mcb), the lacZ mRNA levels are considerably reduced and the cell cycle-dependent modulation of expression is lost (Fig. 5D,E). Again, Cln2 mRNA levels were also monitored as control for cell cycle progression and showed well-synchronized cells with a peak of $\mathrm{Cln} 2$ mRNA expression at 20 and $40 \mathrm{~min}$ followed by a decrease at 60 and $80 \mathrm{~min}$ (Supplemental Fig. S4). These results show that the MCB motifs in E-region of the TLC1 promoter can confer cell cycle-regulated transcription to a heterologous gene. We therefore conclude that the area located at -85 to -144 (E) in the TLC1 promoter drives the cell cycle-regulated transcription of the telomerase RNA.

\section{DISCUSSION}

The data presented here indicate that the very low steadystate level of the telomerase RNA in budding yeast is not simply due to a constitutively weak promoter but, instead, is the product of balancing the competing effects of a dynamic set of repressor and enhancer elements. Altering the balance between these elements strongly affected TLC1 RNA expression and telomerase function in vivo, suggesting that transcriptional regulation of TLC1 contributes to telomere homeostasis (Fig. 1; Table 1). On the other hand, none of our altered promoters significantly affected the mature 3 -end (Supplemental Fig. S2; data not shown), indicating that there is little influence of the promoter on the balance between the polyadenylated and nonpolyadenylated variants of the TLC1 RNA.

Transcription is a critical control point for the regulation of gene expression. Part of the information that dictates the expression of a gene is embedded in its promoter region. In yeast, the overall promoter structure of RNA polymerase II-transcribed noncoding RNA genes is very similar to that of mRNAs (Hamada et al. 2001). However, we failed to identify such a structure in the TLC1 promoter area (Supplemental Fig. S1). For example, the weak TATA box consensus sequences at $-75,-171$, and $-221 \mathrm{bp}$ from the transcription start site (Supplemental Fig. S1) appear redundant, and none is essential for transcription. Any of the three sites could be associated with multiple transcription starts in at least six regions spanning $70 \mathrm{nt}$ (Supplemental Fig. S2). Altogether, 


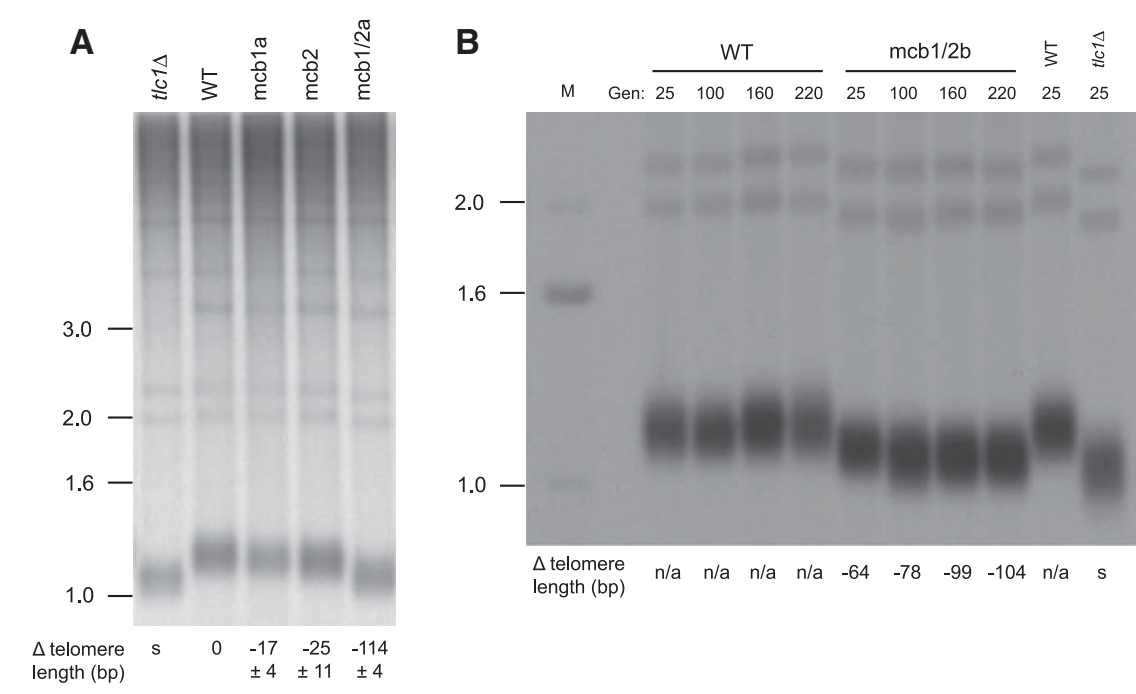

FIGURE 4. Mutation of the Mbp1/Swi4 consensus binding (MCB/SCB) site affects telomere length. (A) Southern blot analysis of telomere lengths of the CSHY76 strain carrying TLC1 (WT) or TLC1 with different mutations in its promoter: mcbla, mcb2, or mcb1/2a. Average changes in $\mathrm{Y}^{\prime}$ telomere length from three independent clones are indicated at the bottom \pm SEM. S denotes senescing cells that have unstable telomere length. (B) Southern blot analysis of telomere length of a strain carrying TLC1 (WT) or tlc1-mcb1/2 (mcb1/2b) grown for 25220 generations. The $t l c 1 \Delta$ strain was grown for 25 generations. Changes in $\mathrm{Y}^{\prime}$ telomere length for cells grown for the indicated number of generations relative to the WT grown for the corresponding number of generations are indicated at the bottom. $\mathrm{n} / \mathrm{a}$ indicates not applicable because the telomeres of these cells were taken as length reference for the corresponding mcb1/2 mutants. $\mathrm{S}$ denotes senescing cells that have unstable telomere length.

these results suggest that the core promoter for TLC1 includes the enhancer element $\mathrm{E}$ and spans regions $\mathrm{E}-\mathrm{F}-\mathrm{G}$ $(+1$ to -144$)$. Further upstream, there is an area conferring transcription repression $(-144$ to -242$)$ (Fig. 1). These findings also suggest that $T L C 1$ is not constitutively transcribed but instead dynamically regulated by competing promoter elements. Furthermore, this particular promoter architecture is highly unusual for an snRNA and therefore sets the TLC1 gene apart from snRNA genes, despite the fact that the mature RNA has several features shared by snRNAs (TMG cap, Sm-binding near 3'-end) (Seto et al. 1999). However, the telomerase RNA is at the center of an RNP of which all protein components occur at levels of only 40-100 molecules per cell (Tuzon et al. 2011). Therefore, if there is a requirement for a coordinated expression of all telomerase components, the promoter driving the snRNA-like TLC1 RNA may have had to evolve to lower expression levels. This hypothesis is also consistent with the fact that not only reduced expression but also overexpression of the TLC1 RNA can disrupt telomere homeostasis, leading to shortened telomeric tracts (Singer and Gottschling 1994). Thus, the resulting TLC1 RNA promoter architecture may reflect an adaptation to the required low expression level.

As expected, reducing transcription initiation rates by deleting promoter elements results in shortened telomeres (Fig. 1C). However, one enhancer element we named $\mathrm{E}$ turned out to be absolutely essential for TLC1 transcription (Fig. 1B).
Phylogenetic comparisons of the TLC1 promoter areas showed that the $\mathrm{E}$ sequences between -85 and -144 are highly conserved (Supplemental Fig. S1). Furthermore, element E contains binding sites for the cell cycle-dependent transcriptional modulators Mbp1/Swi6 and Swi4/Swi6 (Fig. 3). It remains unclear why these sites were not identified in the three published genome-wide studies identifying all potential target genes of Swi4 and Mbp1 (Iyer et al. 2001; Simon et al. 2001; Harbison et al. 2004). Irrespectively, our ChIP results combined with mutational analyses of the E-site show that Mbp1 and Swi4 are indeed bound on the element $\mathrm{E}$ sequences (Figs. $3,4)$. While we cannot rule out the possibility that this region is also necessary for basal transcription, insertion of the region $\mathrm{E}$ sequences does not support the transcription of a reporter gene by itself, suggesting that it is rather an enhancer element (Fig. 2B).

Given the roles of Swi4 and Mbp1 as cell-cycle phase-specific enhancers of transcription, we re-examined the question of a cell cycle-dependent transcriptional regulation of TLC1. Consistent with published results of other groups, we were unable to detect significant changes of TLC1 RNA in samples of synchronized cultures at various points of the cell cycle (Fisher et al. 2004; Mozdy and Cech 2006; data not shown). However, using a method that enriches specifically for RNA that is being actively synthesized, we could show that TLC1 transcription at its genomic locus is induced at the G1/S transition and that region $\mathrm{E}$ sequences can impose the same type of cell cycle-dependent transcription onto a heterologous gene, in our case lacZ (Fig. 5). Previous cell cycle arrest experiments had hinted at a possible cell cycle-regulated abundance of TLC1 RNA with a transcriptional induction at the G1-to-S transition (Chapon et al. 1997). Furthermore, coimmunoprecipitation experiments with extracts from synchronized cultures did reveal a specific increase of a Yku-TLC1 RNA complex in late G1 early S phase (Fisher et al. 2004), which corresponds to the same time frame during which our experiments detect increased transcription of the TLC1 gene. This increase of the YkuTLC1 RNA complex could thus reflect a burst of new TLC1 RNA molecules being transcribed and matured during this time interval. It remains to be explained why this G1/S induction of TLC1 transcription does not result in a measurable increase in TLC1 RNA in the total RNA isolated from cells. One possibility is that the late G1-induced TLC1 transcription only occurs in a minority of cells, and therefore, a relatively minor increase of TLC1 RNA caused by this burst 
A

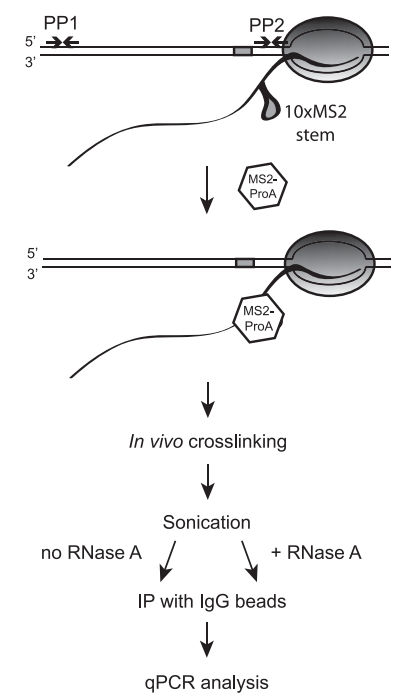

C

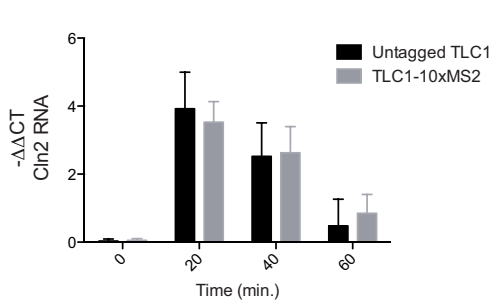

D

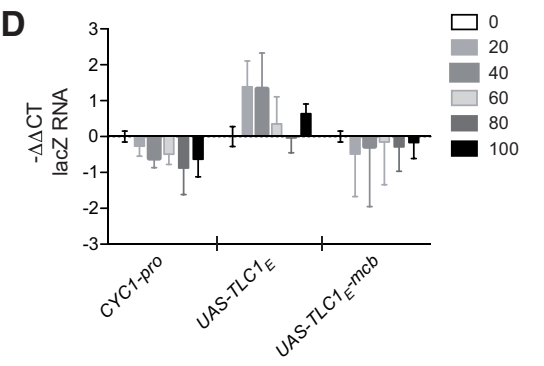

E

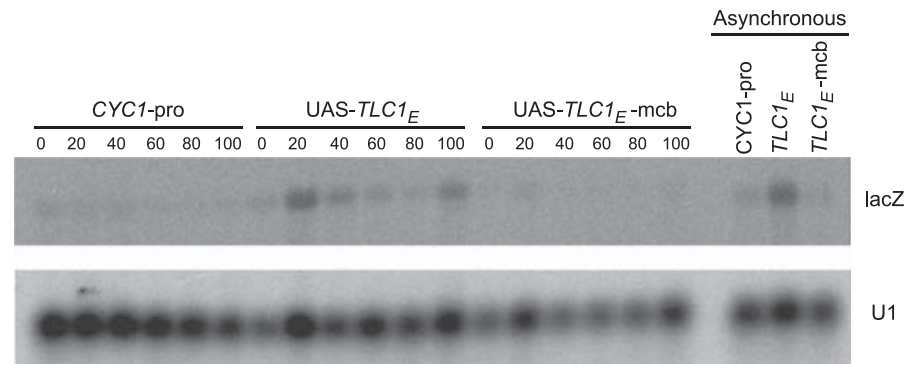

FIGURE 5. The E region containing MCB sites confers cell cycle regulation to TLC1 transcription. (A) Scheme of the RBP-ChIP experiment. Representation of the MS2-tagged (gray box) TLC1 locus transcribed by RNA polymerase II. Following transcription, the MS2 stems are folded, and MS2-ProA proteins are bound to the stems. Performing a chromatin immunoprecipitation (ChIP) with IgG on cells that are transcribing TLC1 will coimmunoprecipitate DNA sequences close to the $3^{\prime}$-end sequence of TLC1. This immunoprecipitation is expected to be dependent on the RNA, treatment with RNase A should abolish immunoprecipitation and is used as control. The primer pair 1 (PP1) overlaps the promoter and the beginning of the gene, whereas the primer pair 2 (PP2) is just downstream from the 10xMS2 tag. (B) qPCR analysis of RBP-ChIP experiments on SBY40 (untagged TLC1) and SBY44 (TLC1-10xMS2) cells at different time points after release from the G1 arrest $(t=0)$. The amount of coprecipitating DNA was measured by qPCR using primer pair 1 (PP1) and primer pair 2 (PP2) located at $1.1 \mathrm{~kb}$ and $60 \mathrm{nt}$ from the MS2 tag, respectively. Each sample was also treated with RNase A to determine the dependence of the immunoprecipitation on the RNA. Average values of three independent biological replicates (two for RNase-treated) normalized against input DNA with SD are shown. (C) qRT-PCR analysis of Cln2 RNA levels at indicated time points for the same experiments as shown in B. CLN2 is a well-known SBF cell cycle-regulated gene and thus serves as a positive control for cell synchronization and activation of the transcription. Average values of three independent biological replicates normalized against Act1 with standard deviation are shown as fold change over $t=0$ (G1). (D) qRT-PCR analysis of lacZ RNA levels at indicated time points. MLY30 cells carrying SLP162 (CYC1 pro-lacZ), SLP164 (CYC1 UAS TLC1E $_{\text {pro-lacZ), or SLP185 (CYC1 UAS }}$ TLC1E-mcbpro-lacZ) were arrested in G1. Synchronized cultures were released, and samples were taken every $20 \mathrm{~min}$. Average values of three independent biological replicates normalized against Actl mRNA with SD are shown as fold change over $t=0(\mathrm{G} 1)$. (E) Northern blot analysis of the same samples as in $D$. may remain below the required threshold for reliable detection. Consistent with this hypothesis, RNA FISH experiments detecting TLC1 RNA show a very high cell to cell variability in total signal (N Laterreur and RJ Wellinger, unpubl.), and the half-life of the TLC1 RNA is $>60$ min, or almost as long as a complete cell cycle (Larose et al. 2007).

So far, the Est1 protein was the only component of the telomerase holoenzyme that was shown to be cell cycle regulated. This regulation occurs at the protein level by a proteasome-dependent degradation in G1 phase, but the Est1 mRNA level is also fluctuating (Osterhage et al. 2006; Larose et al. 2007). Indeed, expression of the Est1 mRNA is sharply induced in late G1/S phase, in parallel with Cln2 RNA (Larose et al. 2007). Curiously, the promoter region of the EST1 gene also contains one overlapping $\mathrm{MCB} / \mathrm{SCB}$ motif and another SCB motif located at -130 and -161 , respectively, from the ATG of EST1 (see gene browser in Saccharomyces genome database). We therefore speculate that both the Est1 mRNA and the TLC1 RNA belong to the same cell cycle-regulated group of gene products that are required during $S$ phase. Given that telomerase can be postulated to be part of the DNA replication machinery, its association with S-phase genes would make biological sense.

In summary, the results presented here show that the E element sequences upstream of the mature $5^{\prime}$-end of TLC1 act as a cell cycle-regulated transcription enhancer. The sequences in element D appear to dampen TLC1 transcription, but this area also overlaps with the divergent promoter of the snR161 gene (Fig. 1). Therefore, we have not analyzed the molecular details regarding how those repressing sequences influence TLC1 transcription. Nevertheless, eventually the combination of positive and negative effects will determine the actual transcription efficacy. We propose that the average very low steady-state level of TLC1 RNA may actually hide a larger than usual variation of TLC1 levels in individual cells and that only a minor fraction of cells induce the cell cycle-regulated transcription of the TLC1 RNA. 


\section{MATERIALS AND METHODS}

\section{Yeast strains}

Strain W303-1A was described earlier (Thomas and Rothstein 1989; Chanfreau et al. 1998). Strain CSHY76 (MATa/a; ade2/ade2; ura3/ura3; leu2/leu2; his3/his3; trp1/trp1; tlc1::LEU2/TLC1; rad52:: TRP1/RAD52) was kindly provided by C. Greider (Le et al. 1999). Strains Z1256 (control strain without tagged proteins), Z1335 (SWI4-myc), and Z1372 (MBP1-myc) were kindly provided by R. Young (Simon et al. 2001). IDY1014-3a (SWI4-myc, TLC1) and IDY1014-6c (SWI4-myc, tlc1-mcb1/2) are derivative spores of Z1335. Strain MLY30 was described earlier (Larrivée et al. 2004). BY4741 (MATa his3 $\Delta 1$, leu2 $\Delta 0$, met15 $\Delta 0$, ura3 $\Delta 0$ ), BY4741-swi4 $\Delta$

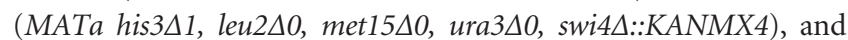

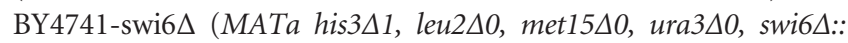
KANMX4) are from the deletion collection (Open Biosystems). The strains for the RBP-ChIP experiment are of the W303 background: SBY40 (MATa can1-100, ura3-1 leu2-3, 112 trp1-1 bar14:: LEU2 HIS3:MS2-ProA) and SBY44 (MATa can1-100, ura3-1 leu2-3, 112 trp1-1 bar1A::LEU2 HIS3:MS2-ProA TLC1-10xMS2). Strains from the "sensu stricto" group, i.e., S288C (S. cerevisiae), SK1 (S. cerevisiae), CBS 432 (Saccharomyces paradoxus), UFRJ 50791 (Saccharomyces cariocanus), IFO 1815 (Saccharomyces mikatae), IFO 1802 (Saccharomyces kudriavzevii), CBS 7001 (Saccharomyces bayanus), and DBVPG 6560 (Saccharomyces pastorianus) were all described earlier (Dandjinou et al. 2004).

\section{Plasmid constructions}

The pADCEN36 plasmid containing wild-type TLC1 is according to the method described previously by Dandjinou et al. (2004). The segments upstream of TLC1 described in Figure 1A were deleted using the SOE (splicing by overlapping) technique (Horton et al. 1993). The final PCR products were digested with SpeI and EcoRI restriction enzymes and cloned into pADCEN26 (a pRS316 plasmid containing a 327-bp ADH1 transcription terminator [Ammerer 1983] inserted into SacI and SpeI upstream of the fragments' cloning sites). This resulted in the generation of the plasmids pADCEN27 $(\Delta \mathrm{C}), \operatorname{pADCEN} 28(\Delta \mathrm{D}), \operatorname{pADCEN} 29(\Delta \mathrm{E}), \operatorname{pADCEN} 30(\Delta \mathrm{F})$, pADCEN31 $(\Delta \mathrm{G}), \operatorname{pADCEN32}(\Delta \mathrm{A}-\mathrm{B}), \operatorname{pADCEN} 33(\Delta \mathrm{C}-\mathrm{G})$, and pADCEN34 $(\triangle \mathrm{A}-\mathrm{G})$. Primers used for PCR amplifications are listed in Supplemental Table S1 of Supplemental Material. The TLC1 promoter-lac $Z$ fusions described in Figure $2 \mathrm{~A}$ were produced by cloning PCR fragments corresponding to the different promoter segments into the SmaI site upstream of the coding sequence of lac $Z$ in SLP092. This resulted in the generation of the following plasmids: SLP152 (A to G), SLP153 (A-B), SLP154 (C-G), SLP155 (D-G), SLP156 (E-G), SLP157 (F-G), and SLP158 (E), respectively. The SLP092 vector was generated by cloning the $A D H 1$ transcription terminator described above into the EcoRI site of YEp353 (Myers et al. 1986). The TLC1-CYC1 promoter constructs described in Figure 2C were generated by cloning different TLC1 promoter fragments into SLP162. The SLP162 plasmid was generated by cloning CYC1 promoter in SLP092 (Guarente and Mason 1983). CYC1 UAS $\Delta$ or SLP163 was created by digesting SLP162 with SmaI and XhoI to remove the upstream activation sequence of CYC1. CYC1 UAS or SLP164 was created by cloning a PCR fragment into the SmaI and XhoI of SLP162. Similarly the plasmids SLP172 $\left(\mathrm{URS}_{A C T 1}\right)$, SLP167 $\left(\mathrm{URS}_{\text {TLC1D }}\right)$, and SLP165 $\left(\mathrm{URS}_{\text {CAR1 }}\right)$ were created by insert- ing the fragments corresponding to ACT1 coding sequence (nt 771 to 843 ), TLC1 region $\mathrm{D}$, and the known repressor of CAR1 (Luche et al. 1990) in the XhoI of SLP162. All the mcb mutations were introduced in the appropriate plasmids using the QuickChange Sitedirected mutagenesis kit (Stratagene) except for SLP183 that was created by introducing mutations in the MCB (mcb1/2b) motifs by using a mutated primer.

\section{Sequence alignment}

Homologous sequences between the PDX3 and CSG2 genes from the "sensu stricto" strains were amplified and sequenced according to the method described earlier (Dandjinou et al. 2004). The intergenic sequences between PDX3 ATG and TLC1 5'-end were aligned using the computer program ClustalW followed by manual optimization (Thompson et al. 1994). The established $5^{\prime}$-end nucleotide of the mature TLC1 RNA and the first nucleotide of the PDX3 coding region were used as anchors for alignment (Dandjinou et al. 2004).

\section{Complementation and telomere length analyses}

The ability of the different TLC1 constructs to complement the deletion of TLC1 was tested using a double mutant spore $(t l c 1 \Delta, \mathrm{rad} 52 \Delta)$ derived from the diploid strain CSHY76. Telomere homeostasis was tested using senescence and telomere length assays according to the method described previously (Dandjinou et al. 2004). Actual variations of telomere lengths were quantified by determining average telomere lengths in indicated samples using a reference standard curve and compared them to the corresponding WT strain.

\section{Primer extension and Northern blot analysis}

Total RNA was prepared according to the method previously described (Larose et al. 2007). Primer extensions were performed according to the method previously described (Abou Elela and Ares 1998) using a primer specific for TLC1 (TLC1-33-49). Extended products were separated on an $8 \%$ denaturing polyacrylamide gel and visualized by autoradiography. Northern blots were performed according to the method previously described (Larose et al. 2007). Total RNA ( 15 or $20 \mu \mathrm{g}$ ) was run on a $4 \%$ polyacrylamide gel or on a $1 \%$ Agarose gel, transferred to a nylon membrane (Hybond $\mathrm{N}+$, GE Healthcare), and visualized by autoradiography using randomly labeled probes or labeled primer corresponding to specific genes. The RNA was quantified using an Instant Imager (Packard). Primers are listed in Supplemental Table S1 of Supplemental Material.

\section{ChIP and RBP-ChIP}

ChIP assays were carried out according to the method described previously (Vodenicharov et al. 2010). Briefly, $50 \mathrm{~mL}$ cultures were crosslinked with $1 \%$ formaldehyde. Cell disruption was achieved using Freezer/Mill 6850 (SPEX CertiPrep) for four cycles of $2 \mathrm{~min}$ at rate 15 separated by 2 min cooling and chromatin sheared by sonication (Misonix; six pulses $20 \mathrm{sec}$ each at $80 \%$ output power). Immunoprecipitations with extracts from the Z1256, Z1335, Z1372, IDY1014-3a, and IDY1014-6c strains were performed using monoclonal anti-Myc antibody (clone 9E10, Roche Diagnostics) with protein G-Sepharose beads (GE Healthcare), while for extracts from the SBY40 and SBY44 strains, magnetic beads (Dynabeads, 
Invitrogen) coated with IgG (MP Biomedicals) were used. After elution, immunoprecipitated DNA was phenol/chloroform extracted and ethanol precipitated before analyses by qPCR.

\section{Cell synchronization}

To synchronize cells in G1, logarithmically growing cultures were incubated with $25 \mathrm{ng} / \mathrm{mL}$ a-factor for $2 \mathrm{~h}$. Cells were washed and resuspended in fresh warm media containing $200 \mu \mathrm{g} / \mathrm{mL}$ pronase. Aliquots were taken every $20 \mathrm{~min}$ and analyzed. The RNA was analyzed by Northern blot and quantified by qRT-PCR.

\section{SUPPLEMENTAL MATERIAL}

Supplemental material is available for this article.

\section{ACKNOWLEDGMENTS}

We thank C. Greider (Johns Hopkins University School of Medicine) for strain CSHY76; R. Young (Whitehead Institute for Biomedical Research) for strains Z1256, Z1335, and Z1372; and E. Bajon and S. Benjira (Wellinger Lab) for strains SBY40 and SBY44. We also thank F. Ménard for technical help, B. Lemieux for help with qPCR analyses, and J.-F. Noël and M. Scott for critical reading of the manuscript. We thank P. Chartrand for fruitful discussions. This work was supported by a grant from the Canadian Institutes of Health Research (MOP-97874). S.A. is a Chercheur National of the Fonds de Recherche Quebec-Santé (FRQ-S), and R.J.W. holds the Canada Research Chair in Telomere Biology.

Received December 10, 2012; accepted April 12, 2013.

\section{REFERENCES}

Abou Elela S, Ares M. 1998. Depletion of yeast RNase III blocks correct $\mathrm{U} 23^{\prime}$ end formation and results in polyadenylated but functional U2 snRNA. EMBO J 17: 3738-3746.

Ammerer G. 1983. Expression of genes in yeast using the ADCI promoter. Methods Enzymol 101: 192-201.

Autexier C, Lue NF. 2006. The structure and function of telomerase reverse transcriptase. Annu Rev Biochem 75: 493-517.

Badis G, Chan ET, van Bakel H, Peña Castillo L, Tillo D, Tsui K, Carlson CD, Gossett AJ, Hasinoff MJ, Warren CL, et al. 2008. A new library of yeast transcription factor motifs reveals a widespread function for Rsc3 in targeting nucleosome exclusion at promoters. Mol Cell 32: 878-887.

Bosoy D, Peng Y, Mian IS, Lue NF. 2003. Conserved N-terminal motifs of telomerase reverse transcriptase required for ribonucleoprotein assembly in vivo. J Biol Chem 278: 3882-3890.

Chanfreau G, Rotondo G, Legrain P, Jacquier A. 1998. Processing of a dicistronic small nucleolar RNA precursor by the RNA endonuclease Rnt1. EMBO J 17: 3726-3737.

Chapon C, Cech TR, Zaug AJ. 1997. Polyadenylation of telomerase RNA in budding yeast. RNA 3: 1337-1351.

Dandjinou AT, Lévesque N, Larose S, Lucier J-F, Elela SA, Wellinger RJ. 2004. A phylogenetically based secondary structure for the yeast telomerase RNA. Curr Biol 14: 1148-1158.

Diede SJ, Gottschling DE. 1999. Telomerase-mediated telomere addition in vivo requires DNA primase and DNA polymerases $\alpha$ and $\delta$. Cell 99: 723-733.

Egan ED, Collins K. 2012. Biogenesis of telomerase ribonucleoproteins. RNA 18: 1747-1759.

Fisher TS, Taggart AKP, Zakian VA. 2004. Cell cycle-dependent regulation of yeast telomerase by Ku. Nat Struct Mol Biol 11: 1198-1205.
Gallardo F, Olivier C, Dandjinou A, Wellinger RJ, Chartrand P. 2008. TLC1 RNA nucleo-cytoplasmic trafficking links telomerase biogenesis to its recruitment to telomeres. EMBO J 27: 748-757.

Gallardo F, Laterreur N, Cusanelli E, Ouenzar F, Querido E, Wellinger RJ, Chartrand P. 2011. Live cell imaging of telomerase RNA dynamics reveals cell cycle-dependent clustering of telomerase at elongating telomeres. Mol Cell 44: 819-827.

Guarente L, Mason T. 1983. Heme regulates transcription of the CYC1 gene of S. cerevisiae via an upstream activation site. Cell 32: 1279-1286.

Guarente L, Ptashne M. 1981. Fusion of Escherichia coli lacZ to the cytochrome $c$ gene of Saccharomyces cerevisiae. Proc Natl Acad Sci 78: 2199-2203.

Hamada M, Huang Y, Lowe TM, Maraia RJ. 2001. Widespread use of TATA elements in the core promoters for RNA polymerases III, II, and I in fission yeast. Mol Cell Biol 21: 6870-6881.

Hampsey M. 1998. Molecular genetics of the RNA polymerase II general transcriptional machinery. Microbiol Mol Biol Rev 62: 465-503.

Harbison CT, Gordon DB, Lee TI, Rinaldi NJ, Macisaac KD, Danford TW, Hannett NM, Tagne J-B, Reynolds DB, Yoo J, et al. 2004. Transcriptional regulatory code of a eukaryotic genome. Nature 431: 99-104.

Horton RM, Ho SN, Pullen JK, Hunt HD, Cai Z, Pease LR. 1993. Gene splicing by overlap extension. Methods Enzymol 217: 270-279.

Iyer VR, Horak CE, Scafe CS, Botstein D, Snyder M, Brown PO. 2001. Genomic binding sites of the yeast cell-cycle transcription factors SBF and MBF. Nature 409: 533-538.

Jamonnak N, Creamer TJ, Darby MM, Schaughency P, Wheelan SJ, Corden JL. 2011. Yeast Nrd1, Nab3, and Sen1 transcriptome-wide binding maps suggest multiple roles in post-transcriptional RNA processing. RNA 17: 2011-2025.

Koch C, Moll T, Neuberg M, Ahorn H, Nasmyth K. 1993. A role for the transcription factors Mbp1 and Swi4 in progression from G1 to S phase. Science 261: 1551-1557.

Kuehner JN, Brow DA. 2006. Quantitative analysis of in vivo initiator selection by yeast RNA polymerase II supports a scanning model. J Biol Chem 281: 14119-14128.

Larose S, Laterreur N, Ghazal G, Gagnon J, Wellinger RJ, Elela SA. 2007. RNase III-dependent regulation of yeast telomerase. J Biol Chem 282: 4373-4381.

Larrivée M, LeBel C, Wellinger RJ. 2004. The generation of proper constitutive G-tails on yeast telomeres is dependent on the MRX complex. Genes Dev 18: 1391-1396.

Le S, Moore JK, Haber JE, Greider CW. 1999. RAD50 and RAD51 define two pathways that collaborate to maintain telomeres in the absence of telomerase. Genetics 152: 143-152.

Lebo KJ, Zappulla DC. 2012. Stiffened yeast telomerase RNA supports RNP function in vitro and in vivo. RNA 18: 1666-1678.

Lin J, Ly H, Hussain A, Abraham M, Pearl S, Tzfati Y, Parslow TG, Blackburn EH. 2004. A universal telomerase RNA core structure includes structured motifs required for binding the telomerase reverse transcriptase protein. Proc Natl Acad Sci 101: 14713-14718.

Luche RM, Sumrada R, Cooper TG. 1990. A cis-acting element present in multiple genes serves as a repressor protein binding site for the yeast CAR1 gene. Mol Cell Biol 10: 3884-3895.

Marcand S, Brevet V, Mann C, Gilson E. 2000. Cell cycle restriction of telomere elongation. Curr Biol 10: 487-490.

McCarroll RM, Fangman WL. 1988. Time of replication of yeast centromeres and telomeres. Cell 54: 505-513.

Mozdy AD, Cech TR. 2006. Low abundance of telomerase in yeast: Implications for telomerase haploinsufficiency. RNA 12: 1721-1737.

Mozdy AD, Podell ER, Cech TR. 2008. Multiple yeast genes, including Paf1 complex genes, affect telomere length via telomerase RNA abundance. Mol Cell Biol 28: 4152-4161.

Myers AM, Tzagoloff A, Kinney DM, Lusty CJ. 1986. Yeast shuttle and integrative vectors with multiple cloning sites suitable for construction of lacZ fusions. Gene 45: 299-310.

Noël J-F, Larose S, Abou Elela S, Wellinger RJ. 2012. Budding yeast telomerase RNA transcription termination is dictated by the Nrd1/ Nab3 non-coding RNA termination pathway. Nucleic Acids Res 40: $5625-5636$. 
Olivas WM, Muhlrad D, Parker R. 1997. Analysis of the yeast genome: Identification of new non-coding and small ORF-containing RNAs. Nucleic Acids Res 25: 4619-4625.

Osterhage JL, Talley JM, Friedman KL. 2006. Proteasome-dependent degradation of Estlp regulates the cell cycle-restricted assembly of telomerase in Saccharomyces cerevisiae. Nat Struct Mol Biol 13: 720-728.

O'Sullivan RJ, Karlseder J. 2010. Telomeres: Protecting chromosomes against genome instability. Nat Rev Mol Cell Biol 11: 171-181.

Raghuraman MK, Winzeler EA, Collingwood D, Hunt S, Wodicka L, Conway A, Lockhart DJ, Davis RW, Brewer BJ, Fangman WL. 2001. Replication dynamics of the yeast genome. Science 294: 115121.

Seto AG, Zaug AJ, Sobel SG, Wolin SL, Cech TR. 1999. Saccharomyces cerevisiae telomerase is an Sm small nuclear ribonucleoprotein particle. Nature 401: 177-180.

Simon I, Barnett J, Hannett N, Harbison CT, Rinaldi NJ, Volkert TL, Wyrick JJ, Zeitlinger J, Gifford DK, Jaakkola TS, et al. 2001. Serial regulation of transcriptional regulators in the yeast cell cycle. Cell 106: $697-708$

Singer MS, Gottschling DE. 1994. TLC1: Template RNA component of Saccharomyces cerevisiae telomerase. Science 266: 404-409.

Smale ST, Kadonaga JT. 2003. The RNA polymerase II core promoter. Annu Rev Biochem 72: 449-479.

Spellman PT, Sherlock G, Zhang MQ, Iyer VR, Anders K, Eisen MB, Brown PO, Botstein D, Futcher B. 1998. Comprehensive identification of cell cycle-regulated genes of the yeast Saccharomyces cerevisiae by microarray hybridization. Mol Biol Cell 9: 3273-3297.

Taba MR, Muroff I, Lydall D, Tebb G, Nasmyth K. 1991. Changes in a SWI4,6-DNA-binding complex occur at the time of $\mathrm{HO}$ gene activation in yeast. Genes Dev 5: 2000-2013.

Taggart AKP, Teng S-C, Zakian VA. 2002. Estlp as a cell cycle-regulated activator of telomere-bound telomerase. Science 297: 1023-1026.
Thomas BJ, Rothstein R. 1989. Elevated recombination rates in transcriptionally active DNA. Cell 56: 619-630.

Thompson JD, Higgins DG, Gibson TJ. 1994. CLUSTAL W: Improving the sensitivity of progressive multiple sequence alignment through sequence weighting, position-specific gap penalties and weight matrix choice. Nucleic Acids Res 22: 4673-4680.

Torchet C, Badis G, Devaux F, Costanzo G, Werner M, Jacquier A. 2005. The complete set of H/ACA snoRNAs that guide rRNA pseudouridylations in Saccharomyces cerevisiae. RNA 11: 928-938.

Tuzon CT, Wu Y, Chan A, Zakian VA. 2011. The Saccharomyces cerevisiae telomerase subunit Est3 binds telomeres in a cell cycle- and Est1-dependent manner and interacts directly with Estl in vitro. PLoS Genet 7: e1002060.

Vodenicharov MD, Laterreur N, Wellinger RJ. 2010. Telomere capping in non-dividing yeast cells requires Yku and Rap1. EMBO J 29: 3007-3019.

Wang Y, Liu CL, Storey JD, Tibshirani RJ, Herschlag D, Brown PO. 2002. Precision and functional specificity in mRNA decay. Proc Natl Acad Sci 99: 5860-5865.

Wellinger RJ, Zakian VA. 2012. Everything you ever wanted to know about Saccharomyces cerevisiae telomeres: Beginning to end. Genetics 191: 1073-1105.

Wittenberg C, Reed SI. 2005. Cell cycle-dependent transcription in yeast: Promoters, transcription factors, and transcriptomes. Oncogene 24: 2746-2755.

Wong JMY, Collins K. 2006. Telomerase RNA level limits telomere maintenance in X-linked dyskeratosis congenita. Genes Dev 20: 2848-2858.

Wu Y, Zakian VA. 2011. The telomeric Cdc13 protein interacts directly with the telomerase subunit Est1 to bring it to telomeric DNA ends in vitro. Proc Natl Acad Sci 108: 20362-20369.

Zappulla DC, Cech TR. 2004. Yeast telomerase RNA: A flexible scaffold for protein subunits. Proc Natl Acad Sci 101: 10024-10029. 

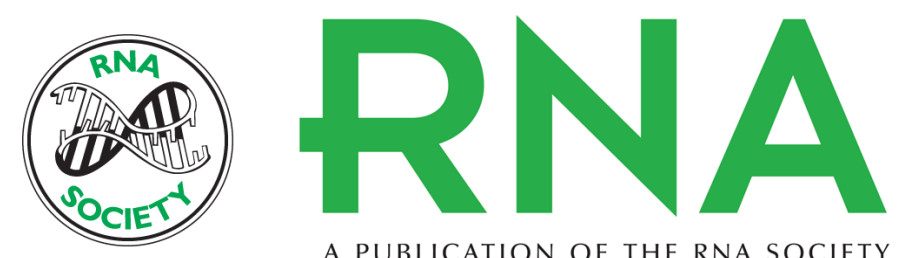

A PUBLICATION OF THE RNA SOCIETY

\section{Cell cycle-dependent transcription factors control the expression of yeast telomerase RNA}

Isabelle Dionne, Stéphanie Larose, Alain T. Dandjinou, et al.

RNA 2013 19: 992-1002 originally published online May 20, 2013

Access the most recent version at doi:10.1261/rna.037663.112

\section{Supplemental http://rnajournal.cshlp.org/content/suppl/2013/05/03/rna.037663.112.DC1 Material}

References This article cites 57 articles, 30 of which can be accessed free at: http://rnajournal.cshlp.org/content/19/7/992.full.html\#ref-list-1

Creative This article is distributed exclusively by the RNA Society for the first 12 months after the Commons License full-issue publication date (see http://rnajournal.cshlp.org/site/misc/terms.xhtml). After 12 months, it is available under a Creative Commons License (Attribution-NonCommercial 3.0 Unported), as described at http://creativecommons.org/licenses/by-nc/3.0/.
Email Alerting Receive free email alerts when new articles cite this article - sign up in the box at the Service top right corner of the article or click here.

\section{|||||||| Providing Precise Solutions for your research.}

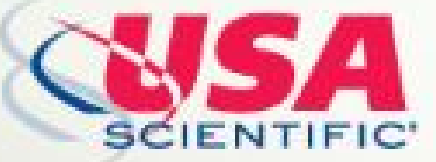

To subscribe to $R N A$ go to:

http://rnajournal.cshlp.org/subscriptions 